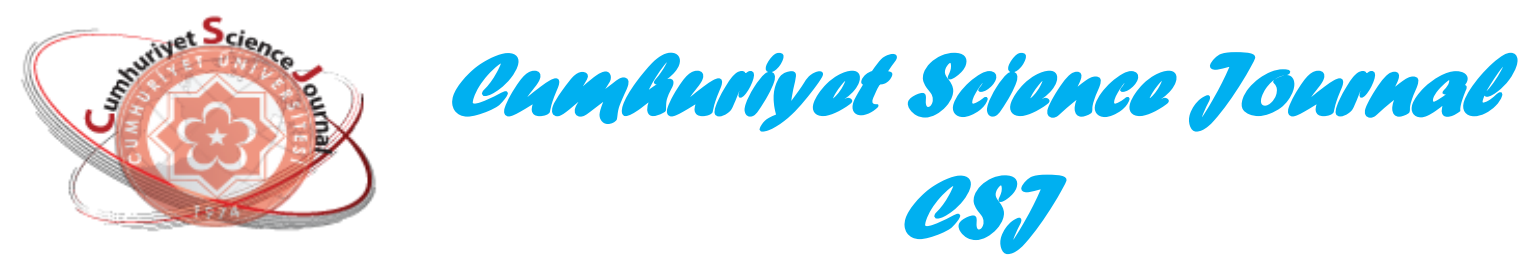

\title{
Archimedean Copula Estimation Parameter with Kendall Distribution Function
}

\author{
Ayşe METIN KARAKAS ${ }^{1 *}$, Murat KARAKAS ${ }^{I}$, Mine DOGAN ${ }^{I}$ \\ ${ }^{1}$ Department of Statistics, Faculty of Art and Science, Bitlis Eren University
}

\begin{abstract}
In the literature, up to now, it is common that for Gumbel, Clayton and Frank calculated Kendall Distribution function and to the extent those applications have been made. In this paper, we made Kendall Distribution function calculation for Ali Mikhail Haq and Joe and in relation that simulation study. We generated dependent gamma distribution. For dependency between these variables we used Archimedean copula. In connection with this, we define basic properties of copulas and their nonparametric method. In this study, to explain the relationship between the variables, five Archimedean copula families were used; Gumbel, Clayton, Frank Joe and Ali Mikhail Haq. We obtained nonparametric estimation of these copula families parameters and the suitable Archimedean copula family for this data set.
\end{abstract}

Keywords: Copula Function, Archimedean Copula, Kendall Tau, Kendall Distribution Function

\section{Kendall Dağglım Fonksiyonu ile Archimedean Copula Parametre Tahmini}

\begin{abstract}
Özet: Literatürde şimdiye kadar Gumbel Clayton ve Frank arşimedyan copula aileleri için Kendall dağılım fonksiyonu hesaplanmış ve bununla ilgili uygulamalar yapılmıştır.Bu makalede Ali Mikhail ve Joe için Kendall dağılım fonksiyonu hesaplayarak simülasyon çalışması yaptık. Gamma dağılımından bağımlı iki değişken ürettik.Bu değişkenler arasındaki bağımlılık yapısı için arşimedyan copula kullandık. Bununla bağlantılı olarak copulanın temel özelliklerini ve parametrik olmayan method tanımladık. Bu çalışmada değişkenler arasındaki bağımlılık yapısını açılamak için beş copula ailesi Gumbel, Clayton, Frank Joe ve Ali Mikhail Haq ailesi kullanıldı.Bu copula ailelerinin parametrik olmayan tahmini ve veri seti için uygun copula ailesini elde ettik.
\end{abstract}

Anahtar Kelimeler: Copula fonksiyonu, Arşimedyan Copula, Kendall Tau, Kendall dağılım fonksiyonu.

\section{INTRODUCTION}

Copulas were first introduced in the context of theory metric spaces. The statistical properties and applications of copulas has been developing in recent years. In 1959 A.Sklar introduced the general notions of a copula (1981 By.B. Schweizer and E.F.Wolff) [6]. A copula function is links univariate marginal to their multivariate distribution. Using Copula function, we model connection between random variables. Copula function is analyzing the dependence structure and it provides degree of dependence structure. Copula is continuous transformation and invariant under increasing. Copulas can be used for modeling dependence in several applied fields such as econometric, finance and actuarial studies. Archimedean copula defines us to reduce the study of multivariate copula to a single univariate function In this article explores for Gumbel, Clayton and Frank calculated Kendall Distribution function and to the extent that applications have

\footnotetext{
Corresponding author. Email address: aysekarakas5767@ gmail.com

http://dergipark.gov.tr/csj C2016 Faculty of Science, Cumhuriyet University
} 
been made. We made $K(u)$ function calculation for Ali Mikhail Haq and Joe and in relation that simulation study. Throughout the paper we work bivariate Archimedean copulas; Clayton, Gumbel and Frank, Joe and Ali Mikhail Haq.

\section{COPULA THEORY}

The copula is defined as $C:[0,1]^{2} \rightarrow[0,1]$ which provides the following conditions

$$
\begin{aligned}
& \quad C(u, 0)=C(0, u)=0 \\
& \text { and } C(u, 1)=C(1, u)=u, \forall u \in[0,1] . \\
& \checkmark \quad\left(u_{1}, u_{2}, v_{1}, v_{2}\right) \in[0,1]^{4} \text {, such that } \\
& u_{1} \leq u_{2}, v_{1} \leq v_{2} \\
& C\left(u_{2}, v_{2}\right)-C\left(u_{2}, v_{1}\right)-C\left(u_{1}, v_{2}\right)+C\left(u_{1}, v_{1}\right) \geq 0 .
\end{aligned}
$$

Ultimately, for twice differentiable and 2increasing property can be replaced by the condition

$$
c(u, v)=\frac{\partial^{2} C(u, v)}{\partial u \partial v} \geq 0
$$

where $c(u, v)$ is the copula density. In the following, for $n$-uniform random $U_{1}, U_{2}, \ldots, U_{n}$ variables, the joint distribution function $C$ is defined

$$
C\left(u_{1}, u_{2}, \ldots, u_{n}, \theta\right)=P\left(U_{1} \leq u_{1}, U_{2} \leq u_{2}, \ldots U_{n} \leq u_{n}\right) .
$$

Here $\theta$ is dependence parameter. $[1,2,3,4,5,6,7,8]$

\subsection{Sklar Theorem}

Let $X$ and $Y$ be random variables with continuous distribution functions $F_{X}$ and $F_{Y}$ which are uniformly distributed on the interval $[0,1]$. Then, there is a copula such that for all $x, y \in R$,

$$
F_{X Y}(X, Y)=C\left(F_{X}(X), F_{Y}(Y) .\right.
$$

The copula $C$ for $(X, Y)$ is the joint distribution function for the pair $F_{X}(X), F_{Y}(Y)$ provided $F_{X}$ and $F_{Y}$ continuous $[1,5,7,8]$.

\subsection{Archimedean Copula}

Let $\varphi$ define a function $\phi:[0,1] \rightarrow[0, \infty]$ which is continuous and provides:

$$
\begin{array}{ll}
\checkmark & \phi(1)=0, \phi(0)=\infty . \\
\checkmark & \text { For all } t \in(0,1), \phi^{\prime}(t)<0, \varphi \text { is } \\
& \text { decreasing, for all } t \in(0,1) \phi^{\prime \prime}(t) \geq 0, \varphi \\
& \text { is convex. }
\end{array}
$$

$\phi$ has an inverse $\phi^{-1}:[0, \infty] \rightarrow[0,1]$, which has the same properties out of $\phi^{(-1)}(0)=1$ and $\phi^{(-1)}(\infty)=0$. The Archimedean Copula is defined by

$$
C(u, v)=\phi^{(-1)}[\phi(u)+\phi(v)] .
$$

Formatınıza uygunsa bu denklemler ortalansın

$$
[2,3,7,8]
$$

\subsection{Gumbel Copula}

This Archimedean copula is defined with the help of generator function $\phi(t)=(-\ln t)^{\theta}, \theta \geq 1$;

$$
C_{\theta}(u, v)=\exp \left(-\left[(-\ln u)^{\theta}+(-\ln v)^{\theta}\right]^{1 / \theta}\right) ; 0 \leq u, v \leq 1
$$

Where $\theta$ is the copula parameter restricted to $[1, \infty)[2]$.

\subsection{Clayton Copula}

This Archimedean copula is defined with the help of generator function $\phi(t)=\frac{t^{-\theta}-1}{\theta}$, $\theta \in[-1, \infty) /\{0\}$ 
$C_{\theta}(u, v)=\left(u^{-\theta}+v^{-\theta}-1\right)^{1 / \theta}$.

Where $\theta$ is the copula parameter restricted to $(0, \infty)[2]$.

\subsection{Frank Copula}

This Archimedean copula is defined with the help of generator function;

$$
\begin{aligned}
& \phi(t)=-\ln \frac{-e^{-\theta t}-1}{e^{-\theta}-1}, \theta \in R /\{0\} \\
& C_{\theta}(u, v)=-\frac{1}{\theta} \ln \left(1+\frac{\left(e^{-\theta u}-1\right)\left(e^{-\theta v}-1\right)}{\left(e^{-\theta}-1\right)}\right)
\end{aligned}
$$

Where $\theta$ is the copula parameter restricted to $(0, \infty)[2]$.

\subsection{Ali Mikhail Haq Copula}

This Archimedean copula is defined with the help of generator function $\varphi(t)=\ln [1-\theta(1-t)] / t$

$C_{\theta}(u, v)=\frac{u v}{1-\theta(1-u)(1-v)}$

Where $\theta$ is the copula parameter restricted to $[-1,1][2]$.

\subsection{Joe Copula}

This Archimedean copula is defined with the help of generator function $\varphi(t)=-\ln \left[1-(1-t)^{\theta}\right]$ $C_{\theta}(u, v)=1-\left[(1-u)^{\theta}+(1-v)^{\theta}-\left((1-u)^{\theta}(1-v)^{\theta}\right]^{1 / \theta}\right.$

Where $\theta$ is the copula parameter restricted to $[1, \infty][2]$.

\subsection{The Nonparametric Estimation}

The Archimedean Copula submits that each copula has statement connections its parameters to related
Kendal Tau and Spearman Rho. In this study only the relationships contains Kendall Tau that given in table.

Table1. The link between Archimedean copulas and Kendall Tau.

\begin{tabular}{ccc}
\hline Family & Range of $\theta$ & $\tau$ \\
\hline Gumbel & $\theta \in[1, \infty)$ & $\frac{\theta-1}{\theta}$ \\
\hline Clayton & $\theta \in[0, \infty)$ & $\frac{\theta}{\theta+2}$ \\
\hline Frank & $\theta \in(-\infty, \infty)$ & $1-\frac{4}{\theta}\left[1-D_{1}(\theta)\right]$ \\
\hline $\begin{array}{c}\text { Ali } \\
\text { Mikhail } \\
\text { Haq }\end{array}$ & $\theta \in[-1,1]$ & $\frac{3 \theta-2}{3 \theta}-\frac{2(1-\theta)^{2} \ln (1-\theta)}{3 \theta^{2}}$ \\
\hline Joe & $\theta \in[1, \infty)$ & $1+\frac{4}{\theta} D_{J}(\theta)$ \\
\hline
\end{tabular}

Here $\mathrm{D}$ is debye functions.

$D_{J}(\theta)=\int_{t=0}^{1} \frac{\left[\ln \left(1-t^{\theta}\right)\right]\left(1-t^{\theta}\right)}{t^{\theta-1}} d t[2]$.

\subsection{Kendall Distribution Function and Properties}

Genest and Rivest [3] proposed a nonparametric method for estimating the dependence function of a pair of random variables for Archimedean copula. The problem of emphasizing a probability model for independent observations $\left(x_{1}, y_{1}\right), \ldots,\left(x_{n}, y_{n}\right)$ from a bivariate non Gaussian distribution function $H(X, Y)$ can be simplified by denoted $H$ and its marginals of $F_{X}$ and $F_{Y}$ and its associated dependence function $C . C$ is the association copula with generator $\phi$ and Kendall Distribution function is defined by

$$
K(u)=\operatorname{Pr}\left\{C\left(U_{1}, \ldots, U_{n}\right) \leq u\right\}
$$

Genest and Rivest give that if $C$ is Archimedean copula, estimation of Archimedean copula is uniquely determined by function on the interval $(0,1)$; 


$$
K(u)=u-\frac{\phi(u)}{\phi^{\prime}(u)}
$$

a nonparametric estimation of $K$ is given by

$$
K_{n}(u)=\sum_{j=1}^{n} I\left\{U_{j} \leq u\right\} / n+1
$$

To define the generator function $\phi$, we take the steps; estimate Kendall Tau correlation coefficient using the non-parametric estimation and nonparametric estimation of $K$. For $K_{n}(u)$ nonparametric estimation of, $K(u)$

i) The nonparametric estimation of Archimedean copula using Kendall Tau correlation coefficient

ii) Define the pseudo-observations

$$
\begin{aligned}
& U_{i}=F_{n}\left(X_{i}, Y_{i}\right) \\
&=\sum_{j=1}^{n} I\left[\left\{X_{j} \leq X_{i}, Y_{j} \leq Y_{i}\right\}\right] / n+1 \\
& i=1,2, \ldots, n
\end{aligned}
$$

$$
K_{n}(u)=\frac{\left(U_{i} \leq u\right)}{n+1}=\frac{\text { number of } U_{i} \leq u}{n+1}
$$

iii) Construct a parametric estimation of $K$

$$
K(u)=u-\frac{\phi(u)}{\phi^{\prime}(u)}
$$

iv) Freez and Valdez the selection of Archimedean copula that fits the data better can be done by minimizing a distance

$\int\left[K_{\phi_{n}}(u)-K_{n}(u)\right]^{2} d K_{n}(u)$

\begin{tabular}{|c|c|c|c|}
\hline Family & Generator $\phi(u)$ & Generator first derivative $\phi(u)$ & $\begin{array}{l}\text { The distribution function } \\
\qquad K(u)=u-\frac{\phi(u)}{\phi^{\prime}(u)}\end{array}$ \\
\hline Gumbel & $(-\ln (u))^{\theta}$ & $-\theta(\ln u)^{\theta-1} \frac{1}{u}$ & $u-\frac{(u \ln u)}{\theta}$ \\
\hline Clayton & $u^{-\theta}-1$ & $-\theta u^{-\theta-1}$ & $u-\frac{\left(u^{\theta+1}-u\right)}{\theta}$ \\
\hline Frank & $-\ln \left(\frac{e^{-\theta u}-1}{e^{-\theta}-1}\right)$ & $\frac{\theta}{1-e^{\theta u}}$ & $u-\frac{\ln \frac{e^{-\theta u}-1}{e^{-\theta}-1}}{\theta}\left(e^{-\theta u}-1\right)$ \\
\hline Ali Mikhail Haq & $\ln [1-\theta(1-u)] / u$ & $\frac{\theta u-\ln [1-\theta(1-u)][1-\theta(1-u)]}{u^{2}[1-\theta(1-u)]}$ & $u-\frac{\ln [1-\theta(1-u)] u[1-\theta(1-u)]}{\theta u-\ln [1-\theta(1-u)][1-\theta(1-u)]}$ \\
\hline Joe & $-\ln \left[1-(1-u)^{\theta}\right]$ & {$\left[\frac{\theta(1-u)^{\theta-1}}{\left[1+(1-u)^{\theta}\right.}\right]$} & $u-\frac{\ln \left[1-(1-u)^{\theta}\right]\left[1-(1-u)^{\theta}\right]}{\theta(1-u)^{\theta-1}}$ \\
\hline
\end{tabular}

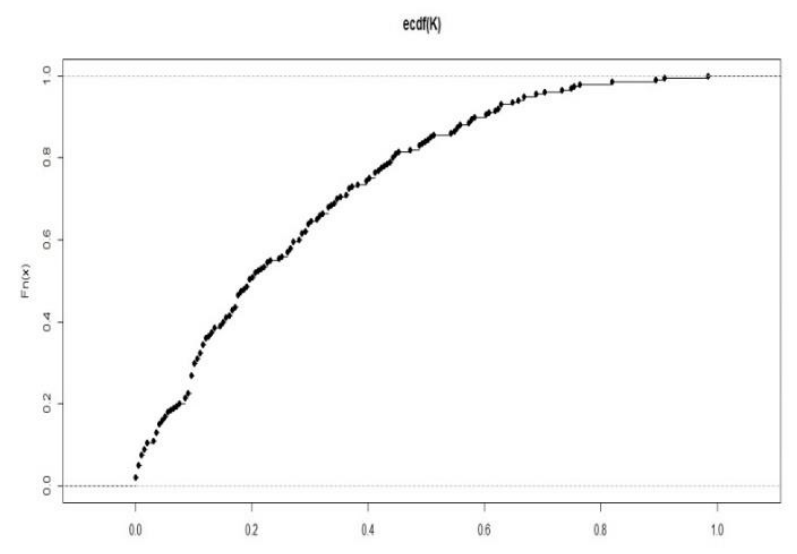

Figure 1. Kendall Distribution Function.

Accordingly, following table give distribution functions of Archimedean copulas.

Table 2. Kendall Distribution functions of Archimedean copulas. 


\section{APPLICATION}

The first section, the method that has been suggested by Genest is given. In this section, Pearson correlation coefficient alternative measures of dependence called rank correlation. We focus on Kendall Tau that has been nonparametric measures of dependence. We have seen that the pairwise correlations are all positive. Namely, Kendall Tau value is positive. This study consists of estimation of Archimedean copula. Genest and Mackay simplified method and lead to estimate the parameters of Archimedean copula that focus on Kendall Tau statistics. This study, up to now, in previous studies, in the literature it is common that for Gumbel, Clayton and Frank calculated Kendall Distribution function and to the extent that applications have been made. We made Kendall Distribution function calculation for Ali Mikhail Haq and Joe and in relation that simulation study. In this simulation study, we generated dependent gamma distribution $X \sim \operatorname{Gam}(1,1)$ and $Y \sim \operatorname{Gam}(1,1)$. Here $n=200$ data were used. We calculated Kendall Tau value in such that 0,042 for $(X, Y)$.Using this that is shown parameters of copulas calculated and results are given in table 3 .

Table 3. Non parametric estimation of Archimedean copula.

\begin{tabular}{cccccc}
\hline Dependency parameter & Gumbel & Clayton & Frank & Ali Mikhail Haq & Joe \\
\hline$\hat{\wedge}$ & 1,0438 & 0,0876 & 0,378 & 0,1802 & 1,076
\end{tabular}

Finally, this study consists of fitting a suitable copula to the data. The results of estimations are given in table 4.

Table 4. Fitting a suitable copula the data.

\begin{tabular}{cccccc}
\hline Pairs & Gumbel & Clayton & Frank & Ali Mikhail Haq & Joe \\
\hline$(X, Y)$ & 0,000135 & 0,000183 & 0,000281 & 0,000149 & 0,000038 \\
\hline
\end{tabular}

\section{CONCLUSION}

In this paper, we modeled the dependence structure between $X \sim \operatorname{Gam}(1,1)$ and $Y \sim \operatorname{Gam}(1,1)$ using Archimedean copula. According to table 4, $K_{n}(u)$ the nonparametric estimation of $K(u)$ is calculated by using pseudo-observations, and using table 2, for Gumbel, Clayton, Frank, Ali Mikhail Haq and Joe respectively $K_{G}(u), K_{C}(u), K_{F}(u)$,
$K_{A M H}(u)$ and $K_{J}(u)$ values calculated. In table $4 K_{n}(u)$ value comparedburayı düzeltemedim. $K_{G}(u) K_{C}(u), K_{F}(u), K_{A M H}(u)$ and $K_{J}(u)$.

Consequently, using the square distance measure, with 0,000038 value, Joe copula gives better fits than Gumbel Clayton, Frank, Ali Mikhail Haq and Joe. 


\section{FIGURES}
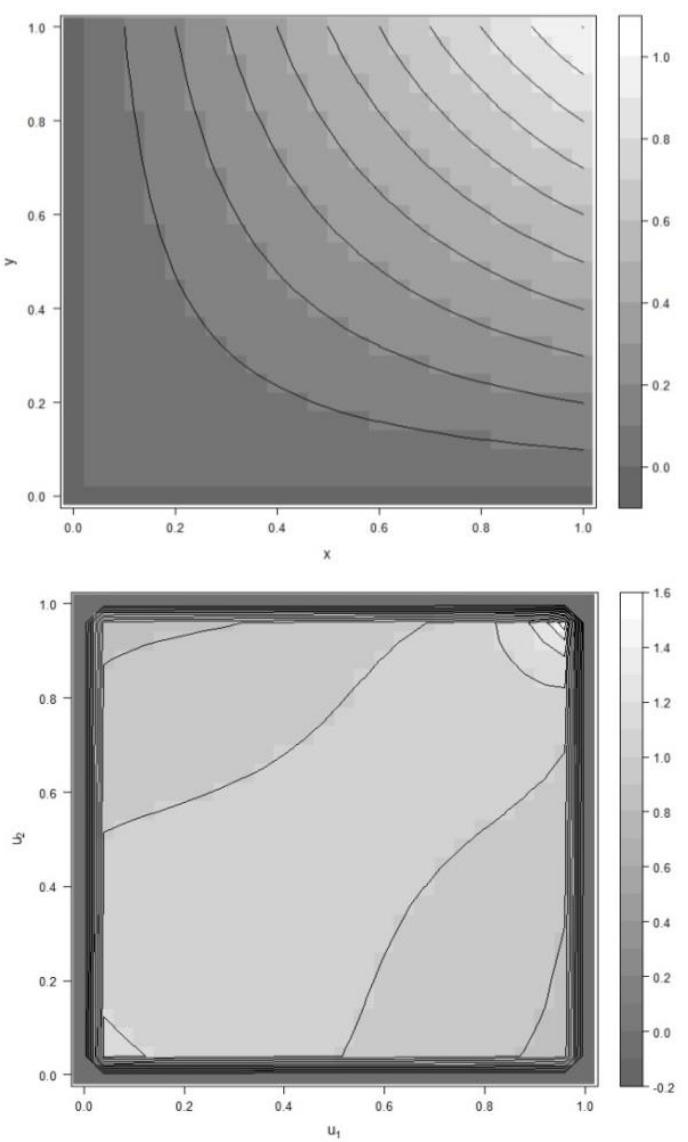

Figures 2. For Gumbel Copula $\theta=1,0438$, respectively dimensional pobability and density function.

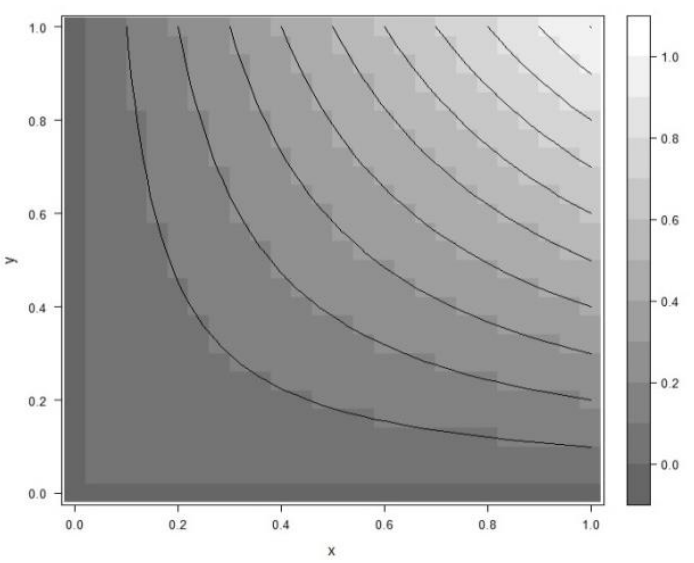

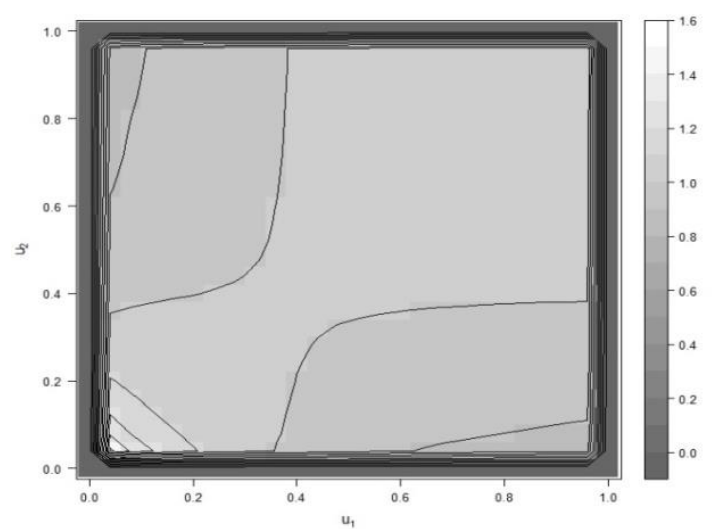

Figures 3. For Clayton Copula $\theta=0,0876$, respectively two dimensional pobability and density function.
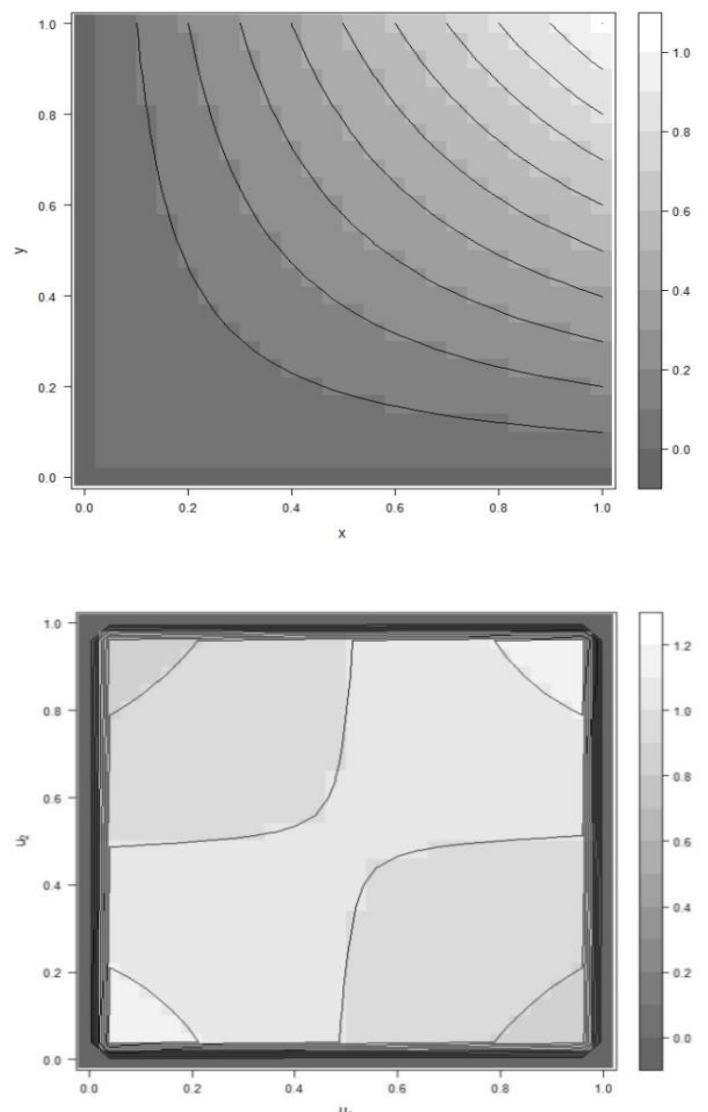

Figures 4. For Frank Copula $\theta=0,378$, respectively two dimensional pobability and density function. 

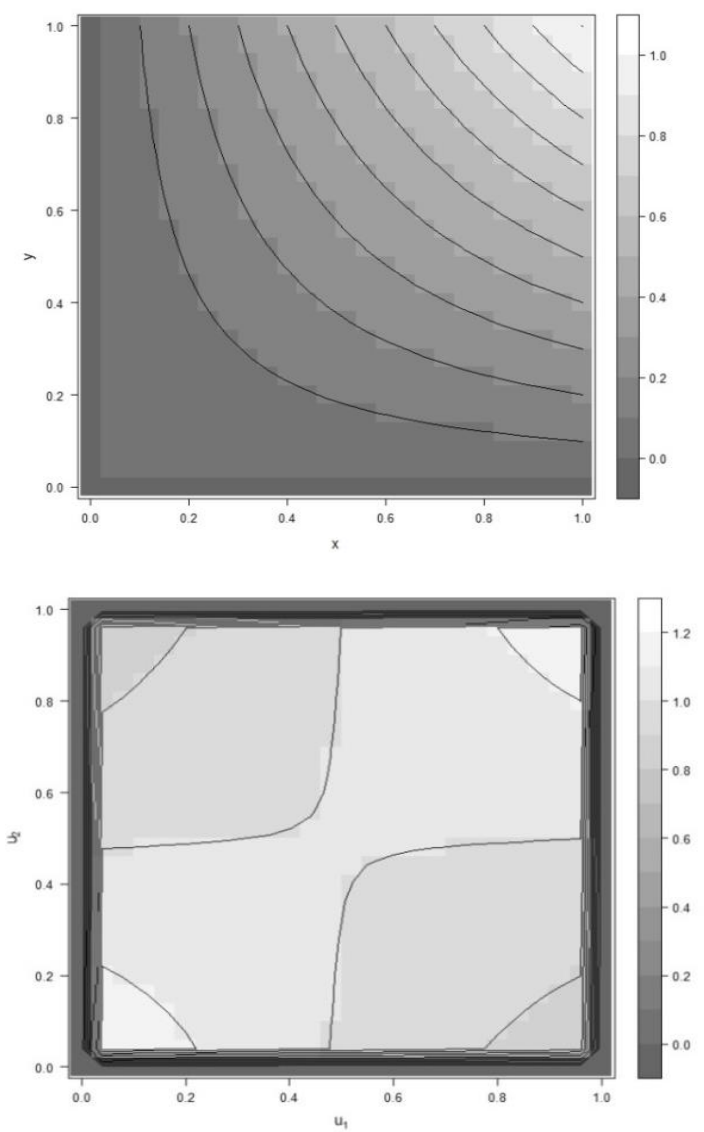

Figures 5. For Ali Mikhail Haq Copula $\theta=0,1802$, respectively two dimensional pobability and density function.

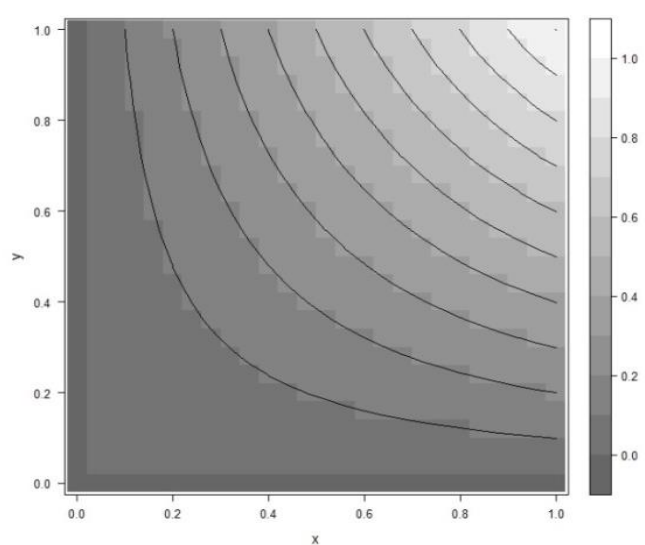

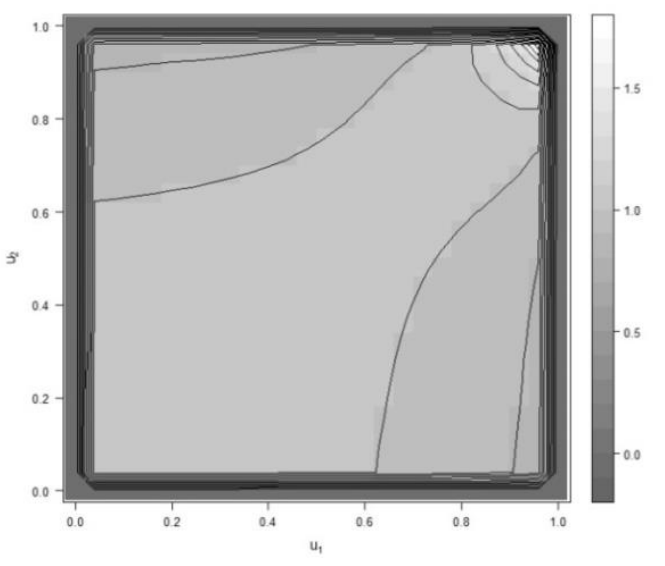

Figures 6. For Joe Copula $\theta=1,076$, respectively two dimensional pobability and density function.

\section{REFERENCES}

[1]. Sklar. Fonctions de Repartition a n Dimensions et Leurs Marges., Publications de I'Institut de Statistique de I'Universite de Paris, 1959, vol 8: pp. 229-231

[2]. Nelsen R. An Introduction to Copulas. Springer-Verlag, New York 1999.

[3]. Genest L.P. Rivest. Statistical inference procedures for bivariate Archimedean copulas. Journal of the American Statistical Association 1993, 88: (423) 1034-1043.

[4]. Genest L.P., MacKay J. The joy of copulas: bivariate distributions with uniform marginal. The American Statisticien 1986 40: 280-283.

[5]. Frees E.W. Valdez E.A. Understanding relationships using copulas. North American Actuarial Journal1998. 2:1-25.

[6]. Schweizer B., Wolff E.F. On nonparametric measures of dependence for random variables. Annals of Statistics 1981, 9:879885.

[7]. Metin A, Çalık S.,Copula Function and Application with Economic Data.. Turkish Journal of Science and Technology. 2012, Vol 7: No 2, 199-204.

[8]. Naifar N. Modeling dependence structure with Archimedean copulas and applications to the iTraxx CDS index. Journal of Computational and Applied Mathematics. 2010 235: 2459-2466. 